\title{
Relations between stress and coping in federal universities nursing teachers of a Brazilian state-analytical study
}

\author{
Raquel Soares Kirchhof ${ }^{1}$, Etiane Oliveira Freitas ${ }^{2}$, Rodrigo Marques da Silva ${ }^{* 2,3}$, Laura de Azevedo Guido ${ }^{2}$, Ana Lúcia \\ Siqueira Costa ${ }^{3}$, Luis Felipe Dias Lopes ${ }^{4}$ \\ ${ }^{1}$ Nursing Department, Integrated Regional University of Alto Uruguai, RS, Brazil \\ ${ }^{2}$ Nursing Department, Public University of Santa Maria, RS, Brazil \\ ${ }^{3}$ School of Nursing, University of São Paulo, São Paulo, Brazil \\ ${ }^{4}$ Production Engineering Department, Public University of Santa Maria, RS, Brazil
}

Received: June 24, 2015

DOI: $10.5430 /$ jnep.v5n12p9
Accepted: July 29, 2015

Online Published: September 1, 2015

URL: http://dx.doi.org/10.5430/jnep.v5n12p9

\begin{abstract}
Objective: To relate stress and coping in the labor environment of Federal Universities nursing teachers in Rio Grande do Sul. Methods: This is a cross-sectional, analytic and quantitative study, conducted with 108 teachers from Rio Grande do Sul state, Brazil. For data collection, there were used: Form with personal/occupational data; Stress Scale at Work, Inventory Coping Strategies. Data were analyzed through the inferential statistics. The project of this investigation was approved by the CEP/UFSM, under protocol number CAAE: 0380.0.243.000-10.

Results: There was predominance of teachers with low stress (93.52\%). The Social Support was the highest average Coping factor $(\bar{X}=1.98, \mathrm{SD}=0.53$ ). There was a significant negative association of low intensity between stress and factors of Acceptance of Responsibility and Escape-avoidance. There was no significant correlation between low stress and coping strategies focused on the problem.

Conclusions: The teachers had low stress and found the use of coping strategies focused on emotions. The results are opposed to the hypothesis of this study that teachers with low stress would use coping strategies focused on problem. Programs aiming to enhance the use of coping strategies, especially those focused on emotion, should be developed to reduce the stress levels of nursing teachers.
\end{abstract}

Key Words: Nursing, Faculty, Stress, Psychological, Adaptation

\section{INTRODUCTION}

When trying to follow the changes from technological advances, social changes and the demands of the labor market, teaching work has changed because, by requiring professionals increasingly qualified, giving high number of students, as well as their diversity led to changes and the need for adaptation by teachers. In addition, teachers are not involved only with activity in the classroom. They serve long working hours with extracurricular demands, problems with students, meetings, participation in councils and administrative positions, which can cause a tiring journey and changes in workers' health. ${ }^{[1-4]}$

\footnotetext{
*Correspondence: Rodrigo Marques da Silva; Email: marques-sm@ hotmail.com; Address: Nursing Department, Public University of Santa Maria, RS, Brazil. 
In this sense, few stressors in teaching environment has been pointed in literature, such as: role ambiguity, work overload connected to the management of students behavior and special educational needs, poor school climate, lack of decision latitude, and limited support from institution. ${ }^{[1-5]}$ Also, they need to teach with a limited physical structure, a lot of students into the rooms, a notable pressure for scientific production, and with several students from different degrees under their scientific advising. In order to meet the stressors in the workplace, some studies have sought to evaluate the stress on teachers and identified the major stressors wage conditions, lack of infrastructure (inadequate lighting, lack of materials), the journey of excessive work, excessive students in the classroom, the noise, the conflicting relations, among others. ${ }^{[6-10]}$ Study conducted with Tunisian professors found that the professional stressors most reported by the teachers were: bad working conditions $(80.3 \%)$, overload work $(75.2 \%)$, administrative difficulties $(70.4 \%)$, difficulties with pupils and their relatives $(64.4 \%)$ and finally organizational factors $(57.1 \%) .^{[11]}$

In the case of teaching nursing, having nursing degree, aimed to take care of patients, which puts him in position susceptible to stress by setting their profession in dealing with extreme situations of life and death. They are responsible to supervise nursing students in clinical setting at hospitals and primary care services, what may represent a stressful situation due to the error risk offered for students to the patient, especially if they were not being adequately supervised. This makes not only the nursing profession, but also the teaching occupation purposes of study related to stress. ${ }^{[1-4]}$ In this sense, the nursing teacher is doubly exposed to stress, because besides teaching, they guide internships and practice activities, and serves the population from intervention programs in the community. ${ }^{[12]}$ All these situations may be evaluated as stressors for nursing teachers and lead them to stress.

Stress refers to any stimulus from the external or internal environment, which exceed the sources of adaptation of an individual or social group, and to consider the subjectivity of the individual as a determinant of the severity of the stressor. ${ }^{[13]}$ Several researches have been conducted to assess stress levels among teachers in different countries. ${ }^{[14-17]}$ In this sense, a research performed with 949 German teachers attending in primary and secondary schools found that $22 \%$ of them evaluated their occupation as extremely stressful. ${ }^{[14]}$ Other investigation involving English teachers reported high occupational stress in $41.5 \%$ of the teachers' sample when compared to $32 \%$ of nurses, $28 \%$ of managers, and $27 \%$ of administrators. ${ }^{[15]}$ In Italy, researchers found that almost $25 \%$ of full-time teachers ${ }^{[16]}$ and $70 \%$ of temporary teachers ${ }^{[17]}$ presented high perceived stress.

The way of teachers perceiving these stressors and how they confront them depends on their personal and cultural characteristics, needs and experiences as well as their perception of the world. ${ }^{[18]}$ To deal with stress, the teachers use coping strategies, called Coping referring to demands management process from the relative person/environment, evaluating how stressful and emotions that they demand. When perceiving a situation as stressful, the individuals make an evaluation of it, so they can respond adequately to the stressor, in order to fix it or mitigate it. ${ }^{[13]}$ They may be problem-focused, when the mainly intention is solving the problem, or emotion-focused, when the strategies are originated from defensives attitudes, leading individuals to avoid a direct facing to the threat. ${ }^{[13]}$ The choice of coping strategies have different results, as the paradigm that these strategies are useful and the way the subject assesses the situation. ${ }^{[4]}$ So, it is necessary to evaluate them and consider health outcomes and the individual well-being. ${ }^{[4]}$

However, the problem-focused strategies have been considered more effective than those emotion-focused in few settings because they are able to control or eliminate the stressor. The use of effective stragetie to cope with stress is essential because, when individuals are exposed to stressful situation and they do not use effective strategies, negative outcomes from stress are more likely to occur, such as Depression, poor Quality of life and Burnout Syndrome. On this last outcome from stress, an investigation performed with 508 Italian teachers found the presence of substantial levels of emotional exhaustion, being that $19.7 \%$ of them were experiencing Burnout. ${ }^{[19]}$ A research perfoed with 398 high school teachers found that the burnout syndrome was present in $21 \%$ of these professionals and the high emotional exhaustion was found in $27.4 \%$ of cases. ${ }^{[11]}$

Thus, it is understood that stress verify and identify the stressors among nursing teachers can serve as a tool to better understand the relationship between the teaching occupation of nurse and stress. Similarly, knowing the coping strategies of these situations, in this population, it becomes relevant once the effective use of coping strategies can minimize stress and prevent its deterioration as well as the Burnout Syndrome. In addition, there are few studies on stress with teachers in different countries, bur they are focused on those teachers attending in elementary and secondary schools, where few potential stressors, such as research and clinical demands, are not present. The same way, in Brazil, there are few national studies that address this issue related to the teaching of higher education, which could serve as a basis for other studies and contribute to the national literature. 
In this sense, the following hypothesis is defended: Lower stress nursing teachers use coping strategies focused on the problem. This study aimed to relate stress and stress coping in the work environment of nursing teachers.

\section{MeTHODS}

This research was described as a transversal, analytic and quantitative study. Transversal design allows that phenomena can be assessed while they occur, during the data collection, in a specific period of time. The analytic investigations are widely applied to verify associations among facts or events under analysis. The quantitative approach is commonly used and intends to ensure the precision of results, to avoid the analysis distortions and interpretations, and to allow a more secure basis for inferences. ${ }^{[20]}$

The population of this study was composed for nursing teachers from Federal Universities in Rio Grande do Sul - RS: Federal University of Santa Maria (UFSM), North Higher Education Center - RS (CESNORS/UFSM), Federal University of Pampa (UNIPAMPA) Federal University of Rio Grande do Sul (UFRGS), Federal University of Pelotas (UFPEL), Federal University of Rio Grande (FURG), Federal University of Health Sciences of Porto Alegre (UFCSPA). The population eligible for this study was 181 nursing teachers from the Federal University of RS, listed according to the following inclusion criteria: nursing teachers, linked to the Graduate Program in Nursing at the UFSM, CESNORS, UNIPAMPA, UFRGS, UFPEL, FURG and UFCSPA with minimal actuation time of six months in the institution and excluding teachers on leave of any kind or on vacation and temporary teachers or substitutes.

Individuals were approached from May to June 2012 at work, where they were invited to participate in this study after the researcher explanation about the research goals. For those who accepted to participate, we delivered the Term of Free and Informed Consent and a research protocol comprised for: personal and professional data questionnaire, the Stress Scale at Work and the Inventory of Coping Strategies. The research protocols where filled at home and their devolution was scheduled directly with each nursing teacher by researcher.

The Stress Scale at Work was used to check the overall occupational stress. ${ }^{[21]}$ It consists of 23 items that address various stressors and emotional reactions associated with them. Each item in the Scale offers five response options with values ranging from one to five, in Likert scale type: the numbers one to "totally disagree", two for "disagree" three to "partly agree" four to "agree" and five for "totally agree". To analyze

Published by Sciedu Press the data obtained with this instrument, the standardized score according to the following formula was calculated as Figure $1:$

$$
S p=100 *\left(\frac{\sum \text { Valuesresponded }-\sum \text { Minimum Values }}{\sum \text { MaximimVahes }-\sum \text { MinimumValues }}\right)
$$

Figure 1. Formula for calculating the standardized score

For Coping, the Inventory of Coping Strategies ${ }^{[13]}$ was used, translated and adapted to the Brazilian reality. ${ }^{[22]}$ It is composed of 66 items addressing thoughts and actions that individuals use to cope with domestic demands especially in a stressful event, using coping strategies. The response options for each instrument item ranges from zero to three, in Likert scale, where: zero means "I did not use the strategy", one means "I used a little", two means "I used a lot", and three means "I used in large quantities". The Inventory of Coping Strategies is organized into eight Factors: Factor 1 Confrontation, Factor 2 - Removal, Factor 3 - Self-control, Factor 4 - Social support, Factor 5 - Acceptance of responsibility, Factor 6 - Escape and avoidance, Factor 7 - Problem solving and Factor 8 - Positive Reevaluation. To perform the analysis, the average of each factor is calculated, thereby identifying the most used strategy by the teachers. ${ }^{[22]}$

For data analysis, a database in Excel for Windows was built after making double independent typing, using Epi Info version 3.5 to ensure the accuracy. The analysis was made by the Software Statistical Package Program for Social Sciences (SPSS) version 17.0. Descriptive statistics for the qualitative and quantitative variables were used. Normality test and group comparison tests: Kruscal-Wallis test and Dunn test to determine statistical differences between the posts of coping factors. In the correlations between the variables of interest and the results obtained with the scales, they used tables of frequencies and Square Test or Fischer's exact test. For inter-scales correlation by Pearson correlation coefficient was assessed. Statistically significant results were seen with a confidence level of $p>.05$. To analyze the internal consistency of the scales, the Alpha coefficient Cronbach was used.

This study is part of the survey "Stress, coping, burnout, depressive symptoms and Hardiness in nursing faculty and students" and contemplated the provisions recommended by Resolution 196/96 of the National Health Council, ${ }^{[23]}$ which regulates research involving beings humanos 15 and was approved by the CEP/UFSM, under protocol number CAAE: 0380.0.243.000-10. 


\section{RESUlts}

The internal consistency of the scales assessed by the alpha coefficient Cronbach performed satisfactorily (Stress Scale at Work was obtained 0.890 and with Inventory of Coping Strategies was obtained 0.987 ) when values above 7.0 indicate that this is adequate. ${ }^{[24]}$

The population accessed in this study was 107 teachers, representing $59.11 \%$ of the nursing teachers from the Federal University of RS. There was female predominance (94.44\%) and married/with partner $(65.74 \%)$. The average age was 44.8 years old, $\mathrm{SD}=9.84$. Regarding the number of children, $38.97 \%$ of teachers do not have children. The sport is practiced by $52.34 \%$ and $86.92 \%$ of teachers reported having leisure activity.

With regard to the title, the doctoral level prevailed to $68.22 \%$ of the teachers. Working time ranged from 17 to 536 months $(\bar{X}=177, \mathrm{dp}=123, \mathrm{md}=158)$ and work as a teacher in the institution ranged from six to 456 months $(\bar{X}=119$, dp $=$ 117 , $\mathrm{md}=158)$.

Most of the population had low stress $(93.52 \%)$. It was found that $6.48 \%$ of the teachers had high stress. The prevalent stressors for this population are as seen in Table 1 . Table 2 presents the situations of lower average. Table 3 presents the descriptive measures for coping factors.

Table 1. Descriptive measures for situations of higher average of stress scale at work according to nursing teachers (RS, 2013)

\begin{tabular}{|c|c|c|c|c|c|c|}
\hline Items & Stress scale at work situations & Average & Med. & SD* & Min. & Max. \\
\hline 22 & Insufficient time to perform my workload makes me nervous. & 3.39 & 3.50 & 1.30 & 1 & 5 \\
\hline 05 & $\begin{array}{l}\text { I feel angry with disabilities in the dissemination of information on } \\
\text { organizational decisions. }\end{array}$ & 2.78 & 3.00 & 1.27 & 1 & 5 \\
\hline 01 & The way tasks are distributed in my area has made me nervous. & 2.71 & 3.00 & 1.09 & 1 & 5 \\
\hline 10 & I'm in a bad mood by having to work for long hours. & 2.60 & 3.00 & 1.21 & 1 & 5 \\
\hline
\end{tabular}

*Standard-deviation

Table 2. Descriptive measures for situations of lower average of stress scale at work according to nursing teachers (RS, 2013)

\begin{tabular}{|c|c|c|c|c|c|c|}
\hline Items & Stress scale at work situations & Average & Med. & SD* & Min. & Max. \\
\hline 08 & I am bothered by my superior when treat me bad in front of co-workers. & 1.37 & 1.00 & 0.82 & 1 & 5 \\
\hline 04 & I felt uncomfortable with the lack of confidence by my superior about my work. & 1.44 & 1.00 & 0.75 & 1 & 4 \\
\hline 20 & I have been nervous for my superior giving me contradictory orders. & 1.49 & 1.00 & 0.71 & 1 & 4 \\
\hline 21 & I feel irritated that my superior cover up my good work in front of others. & 1.51 & 1.00 & 0.84 & 1 & 5 \\
\hline
\end{tabular}

*Standard-deviation

Table 3. Descriptive measures of coping factors according to nursing teachers (RS, 2013)

\begin{tabular}{lllllll}
\hline Coping Factors & N & Center & Average & SD $^{*}$ & Min. & Max. \\
\hline Social Support & 107 & 1 & 1.95 & 0.52 & 1.00 & 3.00 \\
Problem solving & 107 & 2 & 1.85 & 0.51 & 1.00 & 3.00 \\
Positive Reevaluation & 107 & 3 & 1.79 & 0.47 & 1.00 & 3.00 \\
Self-control & 107 & 4 & 1.72 & 0.43 & 1.00 & 3.00 \\
\hline
\end{tabular}

*Standard-deviation

The highest average factor that is, used by the population was social support. However, when comparing the positions between the inventory factors, it was found through the Dunn method that there is no statistically significant difference between Social Support and factors: Problem Solving, Self-control, Removal and confrontational. Regarding the strategies used less, the factor that showed the lowest average was Escape-avoidance. This factor had not significantly different positions in relation to the factors Positive Revaluation, Removal and confrontational, what can be stated that were the least used.

With regard to the correlation between stress and coping factors, there was a significant negative correlation between low-intensity stress and coping factors: Accepting responsi- 
bility $(r=-0.222, p=.025)$ and Escape-avoidance $(r=-0.299$, $p=.002)$. In coping factors Confrontation, Removal, Selfcontrol, Social support, Positive revaluation, and Problem solving, had not significant correlations with stress.

\section{Discussion}

Stress, according to literature, is affected increasing number of workers and from the 90 s is considered to be a worldwide epidemic. ${ }^{[25]}$ In this sense, the consequences of work stress reflects not only at work, with difficulty of concentration and making decisions, reducing commitment, presenteeism, but also it has an impact on workers' health. It can lead to heart disease, digestive disorders, hypertension, headache, musculoskeletal disorders and others, ${ }^{[26]}$ resulting in losses for the employer and employee.

In this study, the nursing teachers were evaluated, which had low stress $(93.52 \%)$, similarly with other studies. In a research of nursing teachers, out of the 30 participating subjects, 12 said they felt stressed and mentioned how stress causes the professional requirement, intellectual work, pressure situations and tension at work and accumulation of all them, among others. ${ }^{[1]}$

With more outstanding results, other research when questioning whether teachers felt stressed, it received affirmative answers of $76 \%$ of subjects. In addition, the study identified three areas related to stress: work and qualifications, personal/social and home/family, financial and health. ${ }^{[10]}$ In another research, conducted in Rio Grande do Sul, the percentage of teachers from the health area and stressed was $24.2 \%$. In addition, $47.2 \%$ of assessed work as very stressful. ${ }^{[10]}$ Other researchers also studied stress in health care teachers, through the Scope Stress Scale, and found $61 \%$ of teachers with mild stress and $32 \%$ with moderate stress, considered by researchers as a worrying result since a moderate level of stress has significant negative health symptoms. ${ }^{[27]}$

Although in this study the population accessed has not presenting high level of stress, it was sought to identify which stressors are prevalent in this population. Among them, those who had higher averages were "insufficient time to carry out my workload, made me nervous", followed respectively "I am angry with the deficiency in the dissemination of information on organizational decisions", "the way how tasks are assigned in my area has made me nervous" and "I' $\mathrm{m}$ in a bad mood by having to work long hours".

These results are similar in literature with regard to stressors in the teaching profession, as studies have identified at least one of these situations as stressful: the workload, lack of time to accomplish the tasks, collections and institutional pressures, fast pace, accumulation of tasks and extracurric- ular activities, among others. ${ }^{[1,8-10,27,28]}$ The workload was cited in a study with higher education teachers as the major cause of stress at work by presenting the most advanced stages of stress. ${ }^{[8]}$ Thus, it is understood that teaching has some features that are specific to this function, and which are identified as causing stress. There is a need for after school activities program by the volume of work, and the pressures and demands for the teacher as deadlines for delivery of reports, dissemination of research results through publications which take time and cost, among others, leading to stress.

On the other hand, to identify the least stressful situations for teachers, there were found respectively: "I am bothered by my superior when treat me bad in front of my co-workers", "I felt bothered by the lack of confidence my superior has about my work", "I'm bothered by my superior giving me contradictory orders" and "I feel irritated that my superior cover up my good work in front of others". It is observed that the lower stress situations are linked to teaching/superior, which shows that these are well established and have no problems.

Faced with these situations identified as most and least stressful, the teacher makes use of coping strategies with the intention of minimizing or eliminating the situations assessed as stressful. In the cognitive perspective, the coping is divided into two functional categories that are focused coping in emotion and the problem. ${ }^{[6]}$ In this study, the most commonly used strategies were Social Support $(\bar{X}=1.95, \mathrm{dp}=0.53)$, Positive Revaluation $(\bar{X}=1.79, \mathrm{dp}=0.47)$, Self-control $(\bar{X}$ $=1.72, \mathrm{dp}=0.43)$, Acceptance of Responsibility $(\bar{X}=1.60$, $\mathrm{dp}=0.50)$, and Removal $(\bar{X}=1.57, \mathrm{dp}=0.43)$, as there was no statistically significant difference between the centers and the least used strategy was the "escape-avoidance" factor $(\bar{X}$ $=1.36, \mathrm{dp}=0.41$ ).

The strategies most used by teachers were coping factors focused on emotion. The function of coping focused on emotion is driving efforts to a physical level and/or a level of feelings in order to change the emotional state. ${ }^{[13]}$ Thus, it can be said that the function of this strategy is to reduce the unpleasant feeling of a physical state of stress. ${ }^{[29]}$ The use of strategies focused on emotion tends to occur when the situations are not changeable, acting in a palliative way. As an example of this type of strategy, there is to watch television and running among others. ${ }^{[29]}$ In this study, the teachers said they had leisure activities, as well as performing physical activity, which can be considered as coping strategies, focused on emotion.

By comparing the results of this research with other studies, there are different results regarding the use of coping strategies. In a research conducted with Portuguese teach- 
ers in the Autonomous Region of Madeira, it was identified through Coping Job Scale (CJS), the main coping strategies were used by the population were Control or Confrontation (problem-focused), followed respectively of escape or avoidance strategies and symptom management strategies, being similar to coping focused on emotion. However, for Portuguese teachers, the symptoms of Management was the least used strategy. ${ }^{[30]}$

In another research, public school teachers were evaluated regarding the use of coping strategies and gender difference. It was evidenced through the COPE Scale that men use more avoidance strategies toward women, using approach strategies such as Planning Strategy. ${ }^{[31]}$ Moreover, in another study, teachers of municipal schools of the North Coast of RS used coping strategies focused on emotion, ${ }^{[32]}$ approached to the results of this study.

As for the coping strategies less used by teachers, they are related to coping factor Escape-Avoidance. In this, the subject fantasizes about possible solutions to the problem, but does not take actions that may in fact modify them. Thus, efforts are made to escape or avoid the cause of stress. ${ }^{[33]}$ This factor includes coping strategies focused on emotion, which may lead the individual to distance from reality, and consequently be less effective to neutralize or overcome stress. ${ }^{[13]}$ This result is in line with the theoretical reference using in small quantities strategies linked to the escape-avoidance factor, which cannot be effective against stress.

In stress and coping relation, there was a significant negative correlation between stress and coping factors Acceptance of Responsibility ( $r=-0.222, p=.025)$, and Escapeavoidance $(r=-0.299, p=.002)$, meaning that the more teachers use strategies Acceptance of responsibility and Escapeavoidance, the less they evaluate the teaching occupation as stressful. This result confronts the theoretical reference, which states that strategies focused on the problem tend to be resolving and strategies focused on emotion tend to be palliative. With this result, the hypothesis of this study was rejected because there was no correlation between low stress and coping strategies focused on the problem. On the other hand, there was a significant correlation between stress and strategies focused on emotion.

This result can be strengthened by other studies, which also found in their research strategies focused on emotion as with resolving action. In addition, the Inventory of Coping Strategies may have influenced this result since it presents six of its eight factors, focused on emotion, statistically tend to find greater use of coping strategies focused on emotion and not in the problem.

Therefore, with the result of this study, it was suggested to carry out a factorial analysis of the instrument of Inventory of Coping Strategies in order to review the distribution of strategies and a possible reclassification of factors.

\section{Conclusion}

There were $93.52 \%$ of nursing teachers of this study with low stress and $6.48 \%$ with high stress. With regard to situations identified as having greater stress, there are "insufficient time to carry out my workload makes me nervous", followed respectively by "I am angry with the deficiency in the dissemination of information on organizational decisions", "ways how tasks are assigned in my area has made me nervous" and "I'm in a bad mood by having to work long hours". In addition, the situations of lower stress identified among the population addressed relationship issues with the leadership.

In this sense, it is understood that this research disagrees with other studies, to identify more than $90 \%$ of the population with low stress. On the other hand, the research conducted, still using different scales and instruments to measure stress, identified similarities in the causes of stress among teachers. This knowledge becomes an important tool to assess work environments in order to plan and induce changes in an attempt to mitigate the stressors in the workplace.

As for the coping strategies most and least used by teachers, it was found that they are focused on emotion, similar to the theoretical reference. In the associations between low stress and coping factors identified a negative correlation, significant low intensity between stress and coping factors Acceptance of Responsibility $(r=-0.222, p=.025)$ and Escape-avoidance $(r=-0.299, p=.002)$, showing the hypothesis of this study that teachers use in low stress coping strategies focused on the problem. Moreover, this result is not consistent with the theoretical reference that can be explained by statistical probability of finding greater use of strategies focused on emotion compared to strategies focused on the problem since it has the inventory, respectively, in six and two factors.

Stress may increase the risk of other physical (Ex. Sleep Quality and Fatigue) and mental (Ex. Burnout Syndrome and Depressive Symptoms) disorders. In this context, once teachers assessed in this investigation apply coping strategies focused on emotion, which possibly are effective to relieve the stress levels, we believe that these professionals are less likely to experience the negative outcomes of stress. Consequently, we can expect a better impact on teaching quality, on individual productivity at work and on the institutional health 
spent with professional leaving and medical treatments.

The main limitation of the present investigation is stemmed from the study design once cross-sectional studies do not provided an analysis of causality among the phenomena. Thus, we can only state that there is a relation between stress and coping, but we cannot ensure that the use of strategies focused on emotion is factually the cause of low stress found in nursing teachers. Also, although the socioeconomic and learning features are seemed across several Brazilian states, we only assessed nursing teachers from one state, what implies that results need to be taken carefully once they not represent the reality experienced for all Brazilian nursing professors.

In this sense, we recommend that programs aiming to en-

\section{REFERENCES}

[1] Christophoro R, Waidman MAP. Stress and conditions of work: a study with nursing professors. Acta Sci. 2002; 24(3): 757-63.

[2] Goulart JE, Lipp MEN. Stress in teachers from government public schools of fundamental education. Psicol Estud. 2008; 13(4): 847-57.

[3] Silva JP, Damásio BF, Melo AS. The meaning of life and the stress in professorship: a correlational study. Cad Psicol Soc Trab. 2009; 12(1): 111-22. http://dx.doi.org/10.11606/issn.198 1-0490.v12i1p111-122

[4] Pocinho M, Perestrelo CX. An essay on burnout, engagement, and coping strategies in the teaching profession. Educ Pesqui. 2011; 37(3): 513-28.

[5] Zurlo MC, Pes D, Capasso R. Teacher Stress Questionnaire: validity and reliability study in Italy. Psychol Rep. 2013 Oct; 113(2): 490-517. PMid:24597443 http://dx.doi.org/10.2466/03. 16 .PRO. $113 \times 23 z 9$

[6] Ahmady S, Changiz T, Masiello I, et al. Organizational role stress among medical school faculty members in Iran: dealing with role conflict. BMC Med Educ. 2007; 7(14): 2-10. http://dx . doi .org /10.1186/1472-6920-7-14

[7] Martins MGT. Stress Symptoms in Brazilian Teachers. Rev Lusóf Educ. 2007; 10: 109-128.

[8] Sorato MT, Marcomin FE. The University Professor's Perception concerning Stress. Saúde Rev. 2007; 9(21): 33-9.

[9] Miranda LCS, Pereira CA, Passos JP. Stress in nursing professors of a public university. Rev Pesqui Cuid Fundam. 2009; 1(2): 335-44.

[10] Oliveira MGM, Cardoso CL. Stress and university teaching in the health sector. Estud Psicol (Campinas). 2012; 28(2): 135-41.

[11] Chennoufi L, Ellouze F, Cherif W, et al. Stress and burnout among Tunisian teachers. Encephale. 2012 Dec; 38(6): 480-7. PMid:23200614 http://dx.doi .org/10.1016/j.encep. 2011. 12.012

[12] Pereira HOS, Amaral MC, Scorsolini-Comin F. Avaliação de sintomas de estresse em professores universitários: qualidade de vida no fazer docente. Rev Educ: Teor Prát. 2011; 21(37): 71-91.

[13] Lazarus RS, Folkman S. Stress, appraisal and coping. New York: Springer; 1984. hance the use of coping strategies, especially those focused on emotion, into university environment be developed and applied in order to relieve the stress levels of nursing teachers. Based on this, we may expect professors would be less likely to experience negative outcomes from high stress levels, such as Burnout, Depression, poor Quality of Life and absenteeism (work leaving due to illnesses).

\section{ACKNOWLEDGEMENTS}

To the Committee on Higher Education Personnel Monitoring - CAPES, for support through the Social Demand scholarship provided to one of the researchers.

\section{CONFLICTS OF INTEREST DISCLOSURE}

The authors declare that there is no conflict of interest statement.
[14] Unterbrink T, Hack A, Pfeifer R, et al. Burnout and effort-rewardimbalance in a sample of 949 German teachers. Int Arch Occup Environ Health. 2007 Apr; 80(5): 433-41. PMid:17294239 http://dx.doi.org/10.1007/s00420-007-0169-0

[15] Smith A, Brice C, Collins A, et al. The Scale of Occupational Stress: a further analysis of the impact of demographic factors and type of job. Cardiff. Health and Safety Executive. 2000.

[16] Zurlo MC. Stress dimensions of Italian and German teachers: a comparative study with the Effort-Reward Imbalance Model. In: E. Schafroth, M. Nicklaus, C. Schwarzer, \& D. Conte ( Eds.), Italy, Germany, Europe: cultural identities and interdependencies]. Germany: Athena; 2013. 19

[17] Zurlo MC, Pes D. Effort-Reward Imbalance e salute psicofisica degliinsegnanti. G Ital Med Lav Ergon. 2012; 34 (2): 81-7.

[18] Camelo SHH, Angerami ELS. Riscos psicossociais no trabalho que podem levar ao estresse: uma análise da literatura. Ciênc Cuid Saúde. 2008; 7(2): 232-40. http://dx.doi.org/10.4025/cienccuid saude.v7i2.5010

[19] Quattrin R, Ciano R, Saveri E, et al. Burnout in teachers: an Italian survey. Ann Ig. 2010 Jul-Aug; 22(4): 311-8. PMid:21417167

[20] Hulley SB, Cummings SR, Browner WS, et al. Delineando a pesquisa clínica. Porto Alegre: Artmed; 2008

[21] Paschoal T, Tamayo A. Validation of the work stress scale. Estud Psicol (Campinas). 2004; 9(1): 45-52. http://dx.doi.org/10. 1590/S1413-294X2004000100006

[22] Savóia MG, Santana PR, Mejias NP. The Adaptation of Coping Strategies Inventory by Folkman and Lazarus into Portuguese. Psicol USP. 1996; 7(1/2): 183-201.

[23] Brazil. Ministry of Health (BR). National Health Council. Resolution 196/96. Brasília. Official Health Journal. 1996.

[24] Bailar J, Mosteller F. Medical uses of statistics. Boston: Nejem Books; 1992. PMid:1550614

[25] World Health Organization. Global strategy on occupational health for all [Internet]. 1995. Available from: http://www. who.int/oc cupational_health/globstrategy/en/index1.html\#

[26] World Health Organization. La organización del trabajo y el estrés Série protección de La salud de lós trabajadores [Internet]. 2004 
Available from: http://www . who.int/occupational_health/ publications/pwh3sp.pdf

[27] Contaifer TRC, Bachion MM, Yoshida T, et al. Stress among university teachers from the health care area. Rev Gaúch Enferm. 2003; 24(2): 215-25. PMid: 15058826

[28] Botelho SH, Soratto MT. Floral Therapy in Control of Stress Nurse Teacher. Saude Rev. 2012; 12(31): 31-42.

[29] Antoniazzi AS, Dell'Aglio DD, Bandeira DR. O Conceito de Coping: uma revisão teórica. Estud Psicol (Natal). 1998; 3(2): 273-94. http://dx.doi.org/10.1590/S1413-294X1998000200006

[30] Pocinho M, Capelo MR. Vulnerability to stress, coping strategies and self-efficiency among Portuguese teachers. Educ Pesqui. 2009;
35(2): 351-67. http://dx.doi.org/10.1590/S1517-9702200 9000200009

[31] Zaffari NT, Peres VL, Silva JP, et al. Síndrome de Burnout e estratégias de coping em professores: diferença entre gêneros. Psico IESB. 2009; 1(2): 1-12

[32] Mazon V, Carlotto MS, Câmara S. Burnout Syndrome and the confronting strategies in teachers. Arq Bras Psicol (Rio J. 1979). 2008; 60(1): $29-46$

[33] Damião EBC, Rossato LM, Fabri LRO, et al. Ways of coping inventory: a theoretical framework. Rev Esc Enferm USP. 2009; 43(Esp2): 1199-203. 